\title{
The Impact of Personal Characteristics of Architects on their Architectural Work
}

\author{
Ahmed Obralić MA \\ KenanaDemirovića 5, Sarajevo \\ Email: ahmedobralic@hotmail.com \\ FuadĆatović, Ph.D. \\ Trg Ivana Krndelja 11D, Mostar \\ Email: fuad.catovic@unmo.ba
}

Doi:10.5296/ ijld.v6i1.8181 URL: http://dx.doi.org/10.5296/ ijld.v6i1.8181

\begin{abstract}
The aim of this paper is to show an influence of human personalities on their professions and to try to find the best model of an architect. By reviewing the literature related to human competences and project management, the research model is created to find the connection between the influence of human (an architect) characteristics on a profession and the characteristics and personalities that are required for design and architecture in general. The study was conducted among the fourteen architects already involved in the designing process. The findings of study point out that in order to reach high productivity, the personal traits have a very big impact on every segment of job performing. The management of the companies should encourage their employees in maintaining their obligations and provide them with appropriate environment in order to fulfill all challenges. We hope this research will help other researchers, architects in A-eling Company, management and students at International Burch University to be aware of the fact that the personalities (characteristics) influence architects in their architectural work.
\end{abstract}

\section{INTRODUCTION}

There is always a general striving to improve in every field of our life. The needs and requirements of environment that surrounds us, and the architect who actually creates an architectural work is a subject of research when it comes to the improvement in general. Besides, working on something that will have an impact on architect's improvement is crucial, because, architecture is also, despite being a kind of art, a response to the needs of individuals. $\mathrm{S} /$ he needs to organize / lead the process of designing people's area. We witness the presence of different types of individuals working in a particular area. The competences and ability to 
lead a certain project, job are subjects that need to be researched in order to improve the life conditions.

The design of a human living space is a very demanding and responsible work. Many architects struggle to create an own architectural identity. After completing their studies, many of them are faced with a problem of disorientation and rejection in a building market. The architecture requires a model of an architect that will solve any situation set by a market. The main goal of a paper is to find out the ways to improve the life standards of humans, what directly and indirectly is related to an architect and his work. Disability to manage the architectural work or incompetence of an architect should not influence the human living quality.

Dealing with architecture and building is not just a mere designing and making drawings. Architecture is a wide science that includes many disciplines and the architect, who is supposed to be someone that will manage the architectural work within wide field of knowledge and sense. What's more, we tend to present the best model of an architect that will response to all given tasks on a market. It is about the competences that influence the leadership of an architect as a project manager in his/her work, and the things that can be improved in order to have productive work.

\section{Theoretical background}

Personalities or characteristics of an architect in this case represent the competences and ability for doing work. A human competency, is considered as human capability that is required for effective performance. Human competence may represent knowledge, skill or ability, a personal characteristic. Competence is fundamental for work performance. Knowledge represents awareness, information, or understanding facts, rules, principles, guidelines, theories and concepts. Knowledge is a segment built in education process and experience. Skill represents a capacity to perform mental or physical tasks with specified outcome (Marrelli, Tondora\&Hoge, 2005).

The architectural work represent all activities that are related to architecture and designing. Creating architecture is not just setting up a physical configuration, it is a compound of many different activities. Architecture has defined the science and the art of forming human living environment. Architecture has a huge diapason of science and life fields, thus, we consider it as a poly tactic issue or the interface of 3 areas of science: technology, humanities, and art (Iranmanesh, 2012).

\section{Historic evolution of idea}

Through history, an architect is known as one who was directly dealing with a building process. Nowadays, architects are becoming administrative worker and clerks. The architectural needs have also changed through the history. The needs in terms of quantity, volume, content, quality and cost. In order to meet people's needs in contemporary time, an architect needs to have many different skills and abilities. In 1930s, there were studies where 
architect became a leader in whole building system due to the fact that an architect was recognized as a chief person in the whole circle. In 1922, Max Weber wrote on bureaucracy, where a leader possessed power by virtue of his position. A new definition of a leadership was made in 1938 by Chester Barnard. He indicated the ability of superiority over otherswhere s/he impact people's behavior and persuade them to follow a particular course of action (Derue, Nahrgang, Wellman \& Humphrey, 2011).Overtime, many theories of leadership were proposed, such as: Trait theory, Behavioral theory, Great man theory, Theory $\mathrm{X}$ and $\mathrm{Y}$, etc.

Regarding trait theory, Darwin contributed with his scientific study of individual differences in his theory of evolution, Galton made some advanced measurements of individual differences in perception, sensation, human skills and abilities. According to Freud, individual differences rooted in the unconscious as the cause of psychological abnormality (Marrelli, Tondora\&Hoge, 2005).

Thus, we need to struggle to establish the role of knowledge management in architectural projects. In theoretical research, the terms of architecture and knowledge management were defined and connected. They defined architecture as a science that all human deal with it, because they are frequently in environments and spaces that need to be assessed based on architecture and are designed by technology and equipment. Therefore, paying attention to the relevant and useful technical and scientific advances in architecture will enhance human life. Although organizations have paid more attentions to knowledge management, it can be assessed as a useful strategy in organizing development, application, and knowledge production. As a result, academic nature, organizational approach, close relations of architecture with various aspects of humanities, the economy, the broadness of architectural knowledge and attention to the goals of knowledge management for advancing knowledge, its application and direction makes the importance of knowledge management more clear in the field of architecture.

\section{Related theories and models}

\section{Leadership theory}

Since an architect has been recognized as a leader in a particular project as a project manager, personality theory of leadership shows personalities that one leader (architect) needs to possess. We can consider a leadership as a mechanism that makes other people move towards certain goals within organization. Effective leadership is the main key for quality achievement. Leadership is a tool for transforming potential into reality. Ability of a leader is also to propose new paradigms when old ones are lost.

\section{Model of Eysenk}

Eysenk developed three major personality factors. First is extroversion, where extraverts are characterized by sociability, impulsiveness, jocularity, liveliness, optimism and quick-wittedness. Second factor is neuroticism, which stands for anxiety, hysteria and obsessive-compulsive disorder, and the third one is psychoticism where people with high psychoticism are egocentric, aggressive, cold, impulsive etc. (Bligh, 2009). 


\section{The BigFivepersonality model}

This model gives five personality factors that describe the leadership. These five factors are conscientiousness, agreeableness, neuroticism, openness and extraversion, most known as CANOE personality model. Researching Big File personality factors has led to more findings between effective leadership and the following five traits: intelligence, self-confidence, determination, sociability and integrity (Bligh, 2009).

Explainingthefactors, conscientiousnessrepresents a tendencyto be organized, thorough, controlled, decisiveanddependable. Agreeableness is an individual'stendencyto be nurturing, trusting, conformingandaccepting. Neuroticism is a tendencyto be anxious, hostile, depressed, vulnerable, andinsecure. Openness is tendencytoexperience, refersandtendencyto be curious, creativeandinformed. Extraversion is themostimportantfactorthat is thetendencytohave a positiveenergy (Bligh, 2009).

\section{The proposed model:}

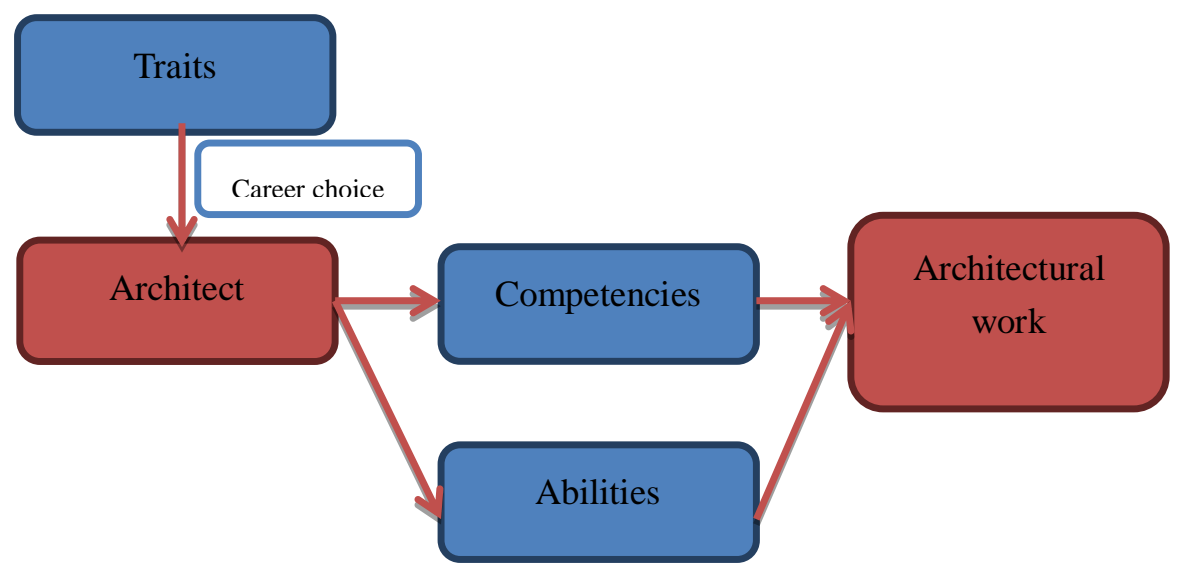

\section{Literature review}

\section{Background studies}

The relationship between personality and career choice has been the main concern of many research. Having in mind that architect is a person that leads the projects, some of below reported studies imply the idea of good leadership. All this factors, the personality, competency, ability, the leadership skills, influence the work of a worker, especially having in mind that job of an architect is a unique profession.

Akisal, Savino and Akisal (2005) made studies of people dealing with different jobs, such as lawyers, managers, architects, journalists and artists. The survey was made among 41 physicians, 30 lawyers, 35 managers, 48 industrialists, 27 architects, 34 journalists, and 48 different kinds of artists. As a result, lawyers and physicians had high rates of dysthymic temperament and OC traits managers, like lawyers and doctors, had high rates of OC traits 
but were different in being very low on cyclothymic and twice as hyperthymic than the CG was. Industrialists had even higher rates of hyperthymic traits. Both architects and artists seemed to have benefited from being cyclothymic (3-4 times higher than CG's); thus, architects had higher levels of OC traits, and artists were less obsessional than the CG was. Despite the foregoing limitations and overlapping attributes in the different professions, they nonetheless emerged having distinct temperamental and personality profiles. Here, the role of cyclothymia in artists and architects has been recognized as significant.

Marcus, Cooper-Thomas and Allpress (2005) dealt with the origins and development of the competency concept, identified three main approaches, benefits of implementing competency models, and their actual application in a sample of New Zealand organizations were presented. After analyzing the competence models in these organizations in New Zealand, it is found that concept of competence is misused. The current use of competency models appears to be strongly weighted towards citizenship rather than technical competencies, and towards promotion of behaviors observed as organizational values and core competencies rather than the assessment and development of technical skills. Instead of supporting capability development through diversity, the competency approach is being used to promote standardization through prescription. The suggestion is that psychologists must play a greater role in informing evidence-based practice in their implementation.

The aim of the study of Kayacetin and Tanyer (2009) was to explore the knowledge management in the practice of architecture. The aim was to investigate knowledge management. The study was made in the Çankaya district of Ankara. Face-to-face interviews were done among the head architects in 15 architectural offices. The interviews were based on a questionnaire which includes issues of learning capabilities, knowledge storing, sharing and deployment mechanisms, and barriers and benefits of managing knowledge. The findings indicated that management of architectural knowledge is considered as very important point of overall productivity in architectural offices. The lack of standard procedure render the knowledge management to be less effective on overall profit and innovation in design. Thus, organizations should continuously collect valuable information, validate and archive them as architectural knowledge and apply best knowledge repositories in projects through a long life-span.

The purpose of Ling's study (2001) was to present a conceptual model for the architects selection by project managers in Singapore. The questionnaire comprised statements regarding attributes that architects may need to possess. The findings of this paper contributed to knowledge by showing conclusively that the Theory of the Firm, which expounds the importance of making profits by minimizing costs through low fees, was not supported in architect selection. It also showed that the Theory of Task Performance and the Theory of Contextual Performance were important for architect. The Network Theory of Embeddedness was only partially supported.

Marrelli, Tondora and Hoge (2005) described a seven-step process for competency modeling. It suggested a conceptual introduction to competency modeling by briefly explaining each step in the process. In the research, it was started with a brief review of key concepts, discuss 
relevant legal issues, and then describe the seven strategies. As a result, to be successful, the project must be carefully planned and supported by the leadership of an organization or profession, and concerted efforts must be made to communicate with those involved or potentially affected. Multiple methods of data collection are optimally used to define the job and to build a competency model, with attention to assuring the reliability and validity of the information gathered, it is also concluded that the development and application of competency models is a proven approach for investing in human resources in order to achieve a more effective and productive workforce.

The study of Kuijpers, Schyns and Scheerens (2006) deals with the question which competencies employees need to possess in order to engage in self-management in their career development. The authors distinguished and operationalized 6 career factors and competencies of self-management in career development. As a methodology of the study, a quantitative study was performed using 1,579 employees in 16 Dutch companies to investigate the relationship between career competencies and career success. The results indicate that, among others, the factors career control and networking are strongly associated with career success. The need for further research on this matter is underlined by the fact that career competencies are now being mentioned more frequently in national policy documents on employability, as well as in the context of policies and programs in educational and labor organizations.

In the work of Hussain, Abbas, Shahzad and Bukhari (2012), the purpose was to conceptualize the importance of personality trait for matching the career choices in new candidates. Themethodology of this study is theoretical analysis of competences that need to be observed and evaluated for certain job. Propositions presented in current paper with presenting the big five competences model will help new incumbents to excel in their careers, and before choosing their career, they will accurately assess their best match. For employers, these propositions will help them to find their optimal choice regarding their requirements so that can prevent their wrong choice to refrain from the future havocs.

In the paper of Yahya (2011), the aim was to examine the relationship between individual's personality traits, career strategies and career satisfaction. The study proposed that career strategies would mediate the relationship between individual's personality traits and career satisfaction. Data were gathered in theNorthern States of Peninsular Malaysia. Results revealed that individual's personality traits and career strategies were correlated with career satisfaction. Results also provided partial support for the mediating role of career strategies (interpersonal attraction, seeking social support and self-nomination) on the relationship between individual's personality traits (extraversion) and career satisfaction.

\section{Methodology}

The statement of problem

Many architects and researchers posed similar questions. In practice, it is obvious that some factors motivate architects more. They sought for particular factors. In order to be a good 
architect, we have to possess characteristics for a particular project and in general.

\section{Participants}

This research was carried out at private company called A-eling. It has been providing a service to all customers who require any kind of activity related to the architecture, civil engineering, installation, central heating system, constructions and workforce. The company is located in Zenica and Sarajevo. The research was done within the spring 2015. There 14 participants working as architects at A-Eling company.The participants were asked for an interview that consisted of six questions. They were also informed about the purpose of the research and later on about the results.

Research Questions:

1. What are the real factors that influence the work of an architect?

2. What are the preferred characteristics for being an architect?

3. What are the characteristics of the architects in general?

4. What are the factors which can influence personality or competence changes in architectural work of participants?

5. How is the architecture work considered by males and females?

6. Considering the personalities, what is the difference between an average architect and the one who wishes to create own architectural identity?

The instrument

The instrument used in this study was an interview designed by the researcher in order to meet the requirements of the research questions and hypothesis stated in the research. Fully-structured interview with open-response questions were conducted. The interview consisted of two parts. In the first part, the participants were required to give their demographical data such as to name the company they work in and the years of working experience; and in the second part they were asked six questions in order to answer the main requirements of the research. The interview was composed of 6 questions. Before collecting the data students were asked permission to participate in this research and they agreed to do it. It was completed within 20 minutes.

\section{Data analysis and Discussion}

The first question in or study was 'What plays an important role while you are doing your work?'. Our participants contributed by giving various answers such as management, clients and colleagues. It points out that working environment and atmosphere can be a main clue for a good job performing. One of the participants mentioned clients' needs, benefits from the projects and motivation factors. Some participants stated that clients' needs, procedure of the 
required projects and management support are particularly important while making a project. It was also stated that management support, clients' clear instructions and needs, and creativity play an important role while they are performing a job.

The second interview question shows their opinion on some characteristics which define architects. They stated that architects are usually patient, creative, agreeable, reliable, open-minded, well-educated, motivated, economic, skillful, and inventive, like the job s/he is doing, self-confident and open to new ideas

To the question 'What are the things which influence personality or cause a change affecting architectural work?' participants stated that those are teamwork, working place, environment, greed, living his/her dreams, family background, salary, the media, career satisfaction and success.

Interesting results was the fact that only one participant does not agree that if an architect male/female it influences the way they work and their outcomes/achievements. He claims that everything is based on the clients' needs and requirements, whereas others agree that gender differences matter in the work, outcomes and achievement. The reason for their opinion is that women are more percussive, reliable, and full of patience, sympathy, they cooperate better with team members.

Last question was on a difference between an ordinary architect and a one who wants to create own architectural identity? They claimed that ordinary architects are mostly used and exploited for quantitative and ordinary projects, however others are more creative; their working attitude differs; those who go beyond the architect work and go after a career are more creative, innovative, pay attention and consider critics as something valuable; they consider art and esthetics more important than money they get and the ordinary service they provide. An architect is always his own boss, a manager because it is himself who is in charge, a good employee/r and a good project provider.

Since studies implied that personal traits have very big impact on every segment of job performing, our study provided similar results to those of Kayacetin and Tanyer (2009) who stated that management of architectural knowledge is considered as very important point of overall productivity in architectural offices.

Our participants argued that academic nature, organizational approach, close relations of architecture with various aspects of humanities, the economy, the broadness of architectural knowledge and attention to the goals of knowledge management for advancing knowledge, its application and direction makes the importance of knowledge management more clear in the field of architecture. Our participants claimed that being part of a good team can provide much better results in the productivity. The fact of money motivation can also play an important role in the job performing.

Our study indicated that personality traits influenced the personals' job performance.

The scientific excellence and importance of the research

Justification of the research in this study is based on its scientific and architectural topicality 
and significance of the research topic which will provide a benefit to the government and the municipality where the company is stated and the new area for the projects. The fact that suggested topic is not processed either directly or by third parties, its treatment represents a real scientific contribution for a scientific corpora. This study will build up a scientific basis for the further researches, management, employee/rs of the companies, the new clients and the students of the architectural faculty. The company can benefit from this study because it provides the current state of their working architects and their attitudes on the personality they own. It also points out the importance of the some personal values a one has to possess. While hiring a new architect this study results can help in evaluating of a new candidates for the position of an architect in A-eling Company.

\section{Limitations of the study}

The limitation of our study is shown in the fact that it was conducted only among fourteen architects, for there are only fourteen of them in A-eling company. Our research can be a scientific basis for the further researches conducted among a bigger number of the participants and companies.

\section{Conclusion}

The study we conducted was on an influence of human personalities on their professions and the best model of an architect. After reviewing the literature related to human competences and project management, the research model is created to find the connection between the influence of human (an architect) characteristics on a profession and the characteristics and personalities that are required for a design and architecture in general. We presented an interview which was done among fourteen architects working at A-eling Company. The interview was designed by a researcher and consisted of six questions in order to answer the main research questions such as: What are the real factors that influence the work of an architect?; What are the preferred characteristics for being an architect?; What are the characteristics of the architects in general?; What are the factors which can influence personality or competence changes in architectural work participants.; How is the architecture work considered by males and females?; Considering the personalities, what is the difference between an average architect and the one who wishes to create own architectural identity?. An interview fully answered the research questions. Since the gathered data really do offer a clear and precise solutions and suggestions, we consider this as a valuable research which can later on be conducted to a bigger number of participants.

We hope our study has contributed to a scientific community, students, and what's more important to the management of A-eling Company. 


\section{Bibliography}

Derue, D.S., Nahrgang, J.D., Wellman, N. \& Humphrey E.S. (2011). Trait and Behavioral Theories of Leadership: An Integration and Meta-Analytic Test of Their Relative Validity, Personnel psychology, 64, 7-52

Bligh, M.C., (2011). PersonalityTheories of Leadership, Encyclopedia of GroupProcesses\&IntergroupRelations, 639-642

Akiskal, K.K, Savino, M., Aksikal, H.S. (2005). Temperament profiles in physicians, lawyers, managers, industrialists, architects, journalists, and artists: a study in psychiatric outpatients, Journal of Affective Disorders 85, 201-206

Markus, L.H., Cooper-Thomas, L..D. \&Allpress, K.N. (2005). Confounded by Competencies? An Evaluation of the Evolution and Use of Competency Models, New Zealand Journal of Psychology Vol. 34, No. 2, 117-126

Kayacetin, N.C., Tanyer, A.M. (2009). Exploring Knowledge Management in the Practice of Architecture: A Pilot Study in the Turkish Capital, MetuJfa, 279-308

Ling, Y.Y. (2001). A conceptual model for selection of architects by project managers in Singapore, International Journal of Project Management 21, 135-144

Oyedele, L.O. (2011). Analysis of architects' demotivating factors in design firms, International Journal of Project Management 31, 342-354

Iranmanesh, L. \&Iranmanesh, A.M. (2012). The Role of Knowledge Management in Architectural Projects, International Journal of Social Science and Humanity, Vol. 2, No. 5, 371-374

Marrelli, A.F., Tondora J. \&Hoge M.A. (2005). StrategiesforDevelopingCompetencyModels, Administration andPolicy in MentalHealth, Vol. 32, Nos. 5/6, 533-561

Kuijpers, M. A. C. T, Schyns, B. \&Scheerens J. (2006). Career Competencies for Career Success, The Career Development Quarterly, Volume 55, 168-178

Trinder J.C. (2008). Competency Standards - A Measure of the Quality of a Workforce, The International Archives of the Photogrammetry, Remote Sensing and Spatial Information Sciences. Vol. XXXVII, 165-167

Hussain, S., Abbas, M., Shahzad K. \&Bukhari S.A.(2012). Personality and career choices, African Journal of Business Management Vol. 6(6), 2255-2260

Udoudoh, S.J. (2012). Impacts of personalitytraits on careerchoice of Information Scientists in Federal University of Technology, Minna, NigerState, Nigeria, International Journal of Library and Information ScienceVol. 4(4), 57-70

Yean, T.F., Yahya, K.K., (2011). Personality Traits and Career Strategies as Determinants of Career Satisfaction, JurnalPengurusan 33, 53 - 59

Allameh, S.M., Ghafari, M. \&Davoodi, S.M.R., (2012). StudyingImpact of PersonalityTraits 


\section{Macrothink}

International Journal of Learning \& Development

ISSN 2164-4063 2016, Vol. 6, No. 1

on JobPerformance (The Case of University of Isfahan'sPersonnel), J. Basic. Appl. Sci. Res., 2(6)6293-6299

Brown, J.D., Cober, R.T.,Kane, K., Levy, P.E. \&Shalhoop J. (2006). Proactive Personality and the Successful Job Search: A Field Investigation With College Graduates, Journal of Applied Psychology, Vol. 91, No. 3, 717-726

Nieken, P. \&Störmer, S. (2010). Personality as Predictor of OccupationalChoice: EmpiricalEvidencefrom Germany

Sutin, A.R., Costa, P.T., Miech, R. \&Eaton, W.W. (2009). PersonalityandCareerSuccess: ConcurrentandLongitudinalRelations, Eur J Pers. 1; 23(2): 71-84

PMA. (2006). IPMA CompetenceBaselineversion 3. Nijkerk: Interntiona Project Management Association. 